\section{The future is now for rare genetic diseases}

We agree with the cautionary note sounded by Roger Collier with respect to the hype surrounding genomic medicine. ${ }^{1}$ In most cases a careful medical and family history combined with a thorough physical examination has as much, and very likely more, clinical prognostic power than does a complete genome sequence. There is, however, one area that we believe even now is delivering on the promise of modern genomics - the oft-neglected realm of orphan (rare) disease.

These individually rare but collectively frequent disorders affect an estimated 1 in 12 Canadians. ${ }^{2}$ Although the genetic etiology of the significant majority of rare disorders is still unknown, the advent of next-generation DNA sequencing is resulting in the identification of rare and ultra-rare disease genes at an ever-increasing rate. This accelerating pace of discovery is best exemplified by the internationally leading Canadian FORGE (Finding of Rare Disease Genes) project, which in its first year alone had identified genes for over 50 rare disorders, affecting thousands of families. ${ }^{3}$

One estimate is that within a decade the clinical and biological impact of mutations in a third of all human genes shall be known, ${ }^{4}$ truly a remarkable wealth of pathogenic knowledge that will profoundly affect our understanding of human biology at a molecular level. Moreover, given the shared phenotypic overlap with more common disorders, insight into these latter conditions might also be forthcoming.

Clinical impact is equally important. Patients might no longer be consigned to costly and often fruitless diagnostic odysseys while confronting an unknown future. Disease gene identification could bring diagnostic clarity (obviating extensive and expensive testing), suggest chance of recurrence within the family and define future clinical course and optimal medical management. Translational research for "common" rare diseases, such as Duchenne muscular dystrophy, spinal muscular atrophy and cystic fibrosis, has led to some thought regarding the generalized formulation to therapeutic approaches for the thousands of the other rare conditions. ${ }^{5}$ Although the promise of genomic medicine lies ahead for complex disorders, the future is now for rare genetic diseases.

\section{Alex MacKenzie MD PhD, Kym M. Boycott MD PhD \\ Children's Hospital of Eastern Ontario, Ottawa, Ont.}

\section{References}

1. Collier R. Popping the genetics bubble. CMAJ 2012;184:637-63.

2. Fundraising tool kit. Toronto (ON): Canadian Organization for Rare Disorders. Available: www .raredisorders.ca/documents/CORDFundraisingToolKit .pdf (accessed 2012 June 21).

3. Finding of Rare Disease Genes Project. Ottawa $(\mathrm{ON})$ : Canadian Pediatric Genetic Disorders Sequencing Consortium; 2010. Available: www.cpgdsconsortium .com/ (accessed 2012 June 21).

4. Samuels M. Saturation of the human phenome. Current Genomics 2010;11:482-99.

5. Beaulieu CL, Samuels ME, Ekins S, et al. A generalizable pre-clinical research approach for orphan disease therapy. Orphanet J Rare Dis 2012;7:39.

CMAJ 2012. DOI:10.1503/cmaj.112-2069

\section{The 5A model for the management of obesity}

In their $C M A J$ article "Managing obesity in adults in primary care," Plourde and Prud'homme propose using the 5A model for the management of obesity. Recently, the Canadian Obesity Network launched a set of tools based on the 5A model, which specifically addresses the needs of practitioners in primary care. $^{2}$

The tools are based on extensive research involving primary care practitioners, obesity experts and patients, and consist of the following steps (slightly different in some aspects from the 5A model presented by Plourde and Prud'homme):

- Ask for permission to discuss weight and explore readiness

- Assess obesity-related risks and "root causes" of obesity

- Advise on health risks and treatment options
- Agree on health outcomes and behavioural goals

- Assist in accessing appropriate resources and providers and arrange follow-up.

The development of these resources was funded through the Canadian Public Health Agency and the Canadian Institutes of Health Research. Toolkits can be obtained through the Canadian Obesity Network (www.obesitynetwork.ca).

\section{Arya M. Sharma MD PhD}

Scientific Director, Canadian Obesity Network and Professor, University of Alberta, Edmonton, Alta.

\section{References}

1. Plourde G, Prud'homme D. Managing obesity in adults in primary care. CMAJ 2012;184:1039-44.

2. New toolkit provides road map for obesity management. Edmonton (AB): Canadian Obesity Network; 2012. Available: www.obesitynetwork.ca /page. aspx ?page $=2895 \&$ app $=182 \&$ cat $1=457 \&$ tp $=12$ $\& \mathrm{k}=$ no\&menu=37(accessed 2012 June 18$)$.

CMAJ 2012. DOI:10.1503/cmaj.112-2062

\section{The authors respond}

Thank you for sharing this new information. ${ }^{1}$ The $5 \mathrm{~A}$ model for the management of obesity recently launched by the Canadian Obesity Network (CON) is an excellent resource that could be added to "Box 5: Resources for physicians and patients" of our article.

As mentioned by Dr. Sharma, there are minor differences to the "classic" 5 As described in our article and those of $\mathrm{CON}$. In the $5 \mathrm{~A}$ model we presented, we mentioned that Ask/Assess can be used interchangeably. Because we aimed to discuss counselling on dietary and physical activity interventions, we decided not to include Ask.

However, not to ignore the importance of Ask, a case report ${ }^{2}$ referenced in Box 3 describes the application of the components of motivational interviewing, including agenda setting, which involves "asking" permission to discuss the issue of interest, and explores readiness for change and strategies to modify barriers to weight management.

Another minor difference with CON's 5A model is about assessing for obesity-related risks and "root causes" 